\title{
ATTITUDES AND YOUNG CONSUMERS' ORGANIC FOOD PURCHASING INTENTIONS
}

\author{
NGUYEN KIM NAM \\ Ho Chi Minh City Industry and Trade College, Vietnam - Email: nguyenkimnam@hitu.edu.vn \\ NGUYEN THI HANG NGA \\ Banking University Ho Chi Minh City, Vietnam - Email: ngath@buh.edu.vn
}

(Received: August 14, 2016; Revised: October 4, 2016; Accepted: October 10, 2016)

\begin{abstract}
The purpose of this study is to examine the impact of attitudes on young consumers' organic food purchasing intentions. The attitude factor in this regard is attitudes towards environment in general and towards organic food consumption behaviors in particular. The results of structural equation modeling (SEM) analysis showed that environmental attitude and environmental concern have a direct impact on organic food purchasing intentions and an indirect impact through attitudes towards organic food. In addition, perceived effectiveness of environmental behavior is also an explanatory factor of consumption intentions of organic food by young consumers. The findings suggest that managers and administrators should concentrate not only on consumers' attitudes toward organic food but also on environmental attitudes, environmental concern, perceived effectiveness of environmental behavior in order to promote organic food consumption by young consumers.
\end{abstract}

Keywords: Attitudes; purchasing intention; environmental concern; organic foods; young consumers.

\section{Introduction}

Sustainable consumption is seen as an inevitable trend in the modern era. It can be regarded as the consumption of goods and services that creates better standards of living, ensures harm-free environment and does not adversely affect the needs of future generations. Sustainable consumption is a broad concept, of which green consumption is a component. Green consumption is more emphasized to environment protection. Presently environmental quality has been reduced, which is illustrated by the global warming, air pollution and natural disasters like tsunami, flood and drought. Therefore, people pay more and more attention to environmental protection issues, including consumers. When consumers are aware of their responsibility in environment protection regarding product consumption, they will be ready to buy friendly-environmental products, especially young consumers (Chen, 2010).

According to Lee (2009), green products are those beneficial to the environment; the behavior of purchasing such environmentfriendly products is called "green purchase behavior". Schlegelmilch et al. (1996) classified green products into recyclable products, animal-free testing products, organically-grown fruit and vegetables, ozone-friendly products, and energy-efficient products. In short, organic consumption is a component of green consumption. Many studies worldwide have focused on youngaged subjects who are target consumers of the future, such as studies by Chen \& Chai (2010), Kim (2011), and Lee (2009). They are highly-educated persons and have a high individual responsibility towards environment. In many developing countries like Vietnam, sustainable consumption in general and green consumption in particular have not been paid due attention, thus remains to be a research gap. Having a large and young population, Vietnam is a potential market for environment-friendly products. 
The movement towards green growth economy has attracted the government's attention recently. Therefore, the business philosophy of green and sustainable produce which adopted by enterprises has become necessary. In this regard, green marketing strategies play an important role. On the one hand, they raise consumers' awareness towards environment but on the other hand, they create a competitive advantage with the use of green business philosophy. In Vietnam, some researches on green consumption behaviors have been conducted. However, they merely investigate green consumption in general, not the consumption in a specific case, for example consumption of organic food. Therefore, the aim of this study is to consider the correlation between environmental attitudes in general, attitudes towards organic food purchase behaviors in particular, and intentions to purchase organic foods by young consumers who are considered as the potential consumers in the future.

\section{Literature review and hypotheses}

The Theory of Planned Behavior (TPB) of Ajzen (1991) is extended from the theory of reasoned action (TRA) of Ajzen \& Fishbein (1980). This theory has been widely used in many areas such as advertising, health care, food choices including organic foods as Chen's research (2007), Dean \& Partners (2008), Gracia \& Magistris (2007), Saba \& Messina (2003), Thøgersen (2007). According to TPB, the planned behavior is explained by factors such as attitudes toward behavior, subjective norms and perceived behavioral control. Attitudes toward behavior are assessed levels of the positive or negative when implementing acts and attitudes that are important predictors of behavioral intentions (Ajzen \& Fishbein, 2005).

Moreover, many studies have been based on cognitive- emotional - behavioral framework such as the three components of attitude model of Schiffman and Kanuk (1987). The three components of attitude consist of cognitive, emotional and behavioral tendencies. Cognitive component refers an individual's knowledge, awareness and beliefs about an object. Emotional component expresses consumers' feelings about an object. Behavioral tendencies component represents to consumers' consumption trend. Based on this framework, several studies on green consumption's mentioned factors related to the ecological environment, such as awareness of the effective environmental actions, concern for the environment and attitude towards the environment to predict green purchase intention. Attitude towards the environment is defined as the assessment about awareness of the environmental values (Lee, 2009). Yeung (2005) suggested that concern for the environment refers to an attribute of emotional, expressing anxiety, passion and attention to environmental consequences. According to Taylor \& Ahmed (1974), perceived effectiveness of environmental behaviour is understood as consumers' confidence that they can contribute effectively in solving environmental problems.

Based on TRA and cognitive - emotional - behavioral framework, and the results derived from some previous studies in the field of organic foods, this study only to examine the impact of the attitude towards the environment; environmental concern; perceived effectiveness of environmental behaviour and attitude towards organic foods affect purchase intention of organic foods of young consumers. Organic food is food produced in a way that complies with organic standards set by national governments and international organizations. Standards vary worldwide; however, organic farming in general, features practices that strive to foster cycling of resources, promote ecological balance, and conserve biodiversity. Organizations regulating organic products may choose to restrict the use of certain pesticides and fertilizers in farming. In general, organic foods are usually not processed using irradiation, industrial solvents or synthetic food additives. 
Attitude towards organic foods (A)

Attitude toward behavior is the degree to which performance of the behavior is positively or negatively valued; the output of the behavior depends on the expectations and beliefs of individuals (Ajzen \& Fisbein, 1980). In the field of green consumption, previous studies have shown that attitude towards green purchase behavior positively influenced the intention to buy green products. Research in the field of organic food as Chen (2007), Dean \& Partners (2008), Saba \& Messina (2003), Thøgersen (2007) have also found that attitude towards behavior has a positive relationship with the purchase intention of organic food of consumers. Referencing from existing literature, it is thus hypothesized that:

H1: Attitude towards organic food (A) positively influences the purchase intention of organic foods (I).

\section{Environmental attitude (EA) and} Environmental concern (EC)

Lee (2008) suggests that environmental attitude related to individual evaluation values for environmental protection. In other words it is an assessment of the personal awareness of the environmental protection values. In green consumption, Chen \& Chai (2010) suggests that buying decisions are often based on consumers' attitude towards the environment. Findings of Lee (2008) showed the higher of attitude towards the environment the higher of the green purchase intention behavior. Similar to findings of Lee (2009) also says that the environmental attitude has positively influence to the green purchase behavior.

Environmental concern shows emotions related to environmental issues (Lee, 2008), in other words the environmental concern mentions of an emotional attribute, expressing anxiety, passion and attention to the environmental consequences (Yeung, 2005). Findings of Lee (2008) and Lee (2009) show that environmental concern has positively influence to the green purchase behavior. In the green consumption, Kim \& Choi (2005) suggests that consumers who have higher concern for the environment are more likely to buy these products than consumers who are less interested in the environment.

Environmental concern is also seen as a form of attitude. Therefore, Bamberg (2003) suggests that environmental concern is considered as the general attitude towards the environment but does not mention a specific attitude for an object or a specific action on the environment. That general attitude expresses a valuation of consumers in terms of reason and sentiment towards environmental protection issues. Based on the assumption of Ajzen \& Fishbein, we can assume that the general attitude does not affect the specific behavior but has an important indirect effects, Bamberg (2003) proposes that environmental concern element indirectly impacts intention actions through a specific attitude. Results of Bamberg test model (2003) shows concern for the environment as a form of general attitude to the environment and indirectly affect purchase intention through intermediary role of attitude towards green purchase behavior. Referencing from existing literature, it is thus hypothesized that:

H2: Environmental attitude (EA) positively impacts on purchase intention of organic foods (I).

H2a: Environmental attitude (EA) positively impacts on attitude towards organic foods $(A)$.

H3: Environmental concern (EC) positively impacts on the purchase intention of organic foods (I).

H3a: Environmental concern (EC) positively impacts on attitude towards organic foods $(A)$.

Perceived effectiveness of environmental behaviour (PCE)

Perceived effectiveness of environmental behaviour mentions the extent to which individuals believe that their actions will make a difference in addressing environmental problems (Kim \& Choi, 2005). According to Taylor \& Ahmed (1974), the PCE is understood as consumer confidence in 
which they can contribute effectively in solving environmental problems. Kim \& Choi (2005) suggests that the attitude or environmental concerns of consumers can not easily be converted into environmental protection actions. However, when an individual has a strong belief that awareness of their environmental behavior can lead to positive results, then they are likely to engage in environmental behaviors. Many studies have used PCE to explain the intention to buy green products and the results show that the higher PCE consumers will have a positive behavior on the environment (Bamberg, 2003; Lee, 2008; Vermeir \& Verbeke, 2007). Therefore, the following hypotheses are offered:

H4: Perceived effectiveness of environmental behaviour (PCE) positively influences purchase intention of organic foods (I).

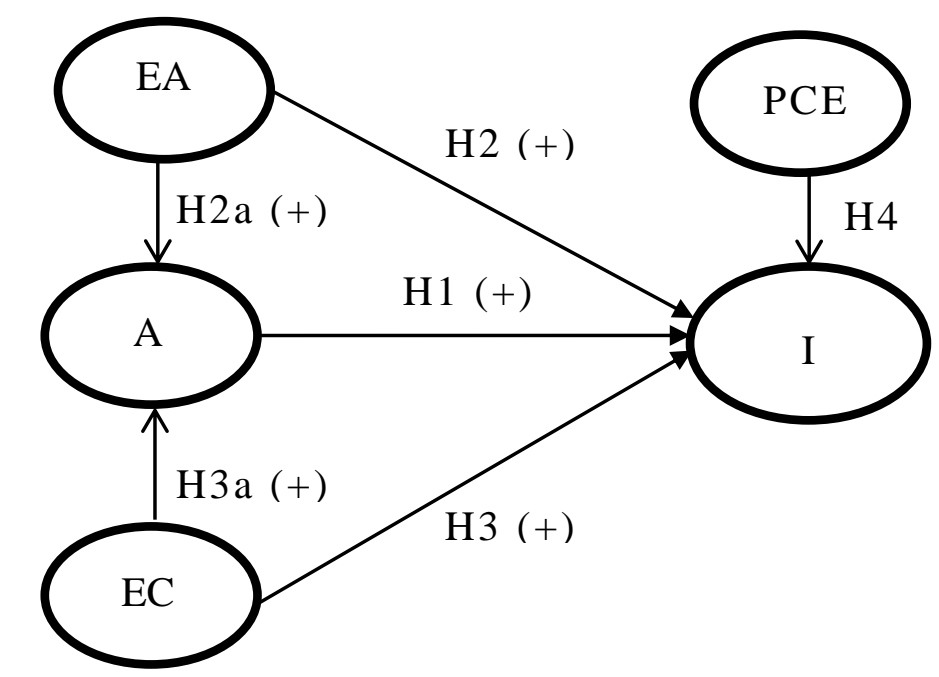

Figure 1. Research framework for organic food purchase intentions

\section{Research methodology}

Data is collected in Ho Chi Minh City by consumer questionnaire surveys. Based on convenience sampling, 459 young consumers in Ho Chi Minh City were surveyed to test the measurement and theoretical models. The sample included 362 (78.9 percent) female and 97 (21.1 percent) male consumers. In terms of age, young consumers were aged from 18 to 22 years. All items were measured by a five-point Likert scale, anchored by 1 : strongly disagree and 5: strongly agree. A pilot test was done by 50 respondents to detect any problems and correct them before the actual study is conducted. In this study, we used structural equation modeling (SEM) to test the hypotheses with the support of the software AMOS. Before testing the hypotheses in the SEM, we first calculated the coefficient alpha and performed exploratory factor analysis (EFA) to initially test the scale of reliability and validity. After that, we performed confirming factor analysis (CFA) to assess the measurement model. Finally, we employed SEM analysis to estimate path coefficients for the hypothesized relationships. The scales and questions in the study are based on previous studies in green consumption as Lee (2008), Lee (2009), Kim \& Choi (2005), Taylor \& Todd (1995). Attitude towards organic foods scale comprises three items were based on Taylor \& Todd (1995). Environmental attitude scale comprises two items, perceived effectiveness of environmental behaviour scale comprises two items, environmental concern scale comprises three items and purchase intention of organic foods scale comprises three items were based on Lee (2008), Lee (2009), Kim \& Choi (2005). 


\section{Results and discussion \\ Scale reliability tests and descriptive statistics}

Results of statistical analysis showed that men accounted for $21.1 \%$ and females accounted for $78.9 \%$ in the samples. The average value of the variable EA, PCE and EC is relatively high since it is on level four of the five-point scale. This shows that young consumers strongly believe that their actions can contribute effectively in solving environmental problems. But the average value of the attitude towards organic foods and purchase intention to buy organic foods variable is relatively low in comparison with the remaining variables. Young consumers might have a positive attitude, concern for the environment and believe their actions will contribute positively to the environment but organic foods may still be unfamiliar to them as they are relatively new products in Vietnam market. To assess the reliability of the scale, the study conducts testing the reliability of the scales through Cronbach's Alpha Reliability Coefficient. The results of reliability testing of scale achieve reliability requirements, Cronbach'alpha of EC scale was 0.719; PCE scale is 0.694; EA scale is 0.862; A scale is 0.908 ; I scale is 0.716 .

Table 1

Descriptive statistics

\begin{tabular}{ccccc}
\hline Variables & N & Mean & Std deviation & Cronbach's Alpha \\
\hline PCE & 459 & 4.26 & 0.74 & 0.694 \\
EC & 459 & 4.04 & 0.64 & 0.719 \\
EA & 459 & 4.55 & 0.70 & 0.862 \\
A & 459 & 3.86 & 0.82 & 0.908 \\
I & 459 & 3.56 & 0.64 & 0.716 \\
\hline
\end{tabular}

\section{The results of $C F A$ and $S E M$}

After assessing the scales based on Cronbach's alpha, the study performs Exploratory factors analysis before proceeding Confirmatory factor analysis (CFA). Results of Exploratory factors analysis achieve, including 5 concepts with 13 observable variables. The value of KaiserMeyer-Olkin (KMO) was 0.837 and statistical test for Bartlett test was significant $(\mathrm{p}=$ 0.000). The results of CFA exhibited a good level of fit: $\mathrm{Cmin}=67.58$; $\mathrm{df}=56$; $\mathrm{GFI}=$ 0.978; $\mathrm{CFI}=0.995 ; \mathrm{NFI}=0.973$; $\mathrm{RMSEA}=$ 0.022. All t-tests of the indicator variables were significant at the 0.001 level.

The results of the structural equation analysis indicated that the model achieved a good level of fit: CMIN $=67.112 ; \mathrm{df}=55$; GFI $=0.978 ; \mathrm{CFI}=0.995 ; \mathrm{NFI}=0.972 ; \mathrm{RMSEA}=$ 0.021 . The estimated coefficients in the model structure achieve statistical significance at the level 5\%. Consistent with H1, A variables were found to be positively associated with I variables $\left(\beta_{1}=0.07, \mathrm{p}=0.02\right) \mathrm{H} 2$ posits a positive relationship between EA variables and I variables. This hypothesis was supported $\left(\beta_{2}\right.$ $=0.124, \mathrm{p}=0.011) \mathrm{H} 3$ posits a positive relationship between EC variables and I variables. This hypothesis was supported $\left(\beta_{3}=\right.$ $0.149, \mathrm{p}=0.043)$. Similarly, PCE positive impacts on I variables $\left(\beta_{4}=0.17, p=0.008\right)$ so this hypothesis was supported. $\mathrm{H} 2 \mathrm{a}$ and $\mathrm{H} 3 \mathrm{a}$ hypothesis are supported $(\beta=0.15, \mathrm{P}=0.032)$ and $(\beta=0.26, \mathrm{P}=0.014)$. Thus $\mathrm{A}, \mathrm{EA}, \mathrm{EC}$, PCE variables affect purchase intention of organic foods of young consumers. In which the most influential factor is PCE $\left(\beta_{\text {standarised }}=\right.$ $0.18)$, followed factors were EA $\left(\beta_{\text {standarised }}=\right.$ $0.172)$, EC $\left(\beta_{\text {standarised }}=0.145\right)$ and finally the $\mathrm{A}\left(\beta_{\text {standarised }}=0.127\right)$. 


\section{Table 2}

Estimates of structural equation coefficients

\begin{tabular}{cccl}
\hline Paths & $\begin{array}{c}\text { Parameter value } \\
\text { (unstandardized) }\end{array}$ & P -value & Hypothesis \\
\hline I <-- PCE & 0.170 & 0.008 & Supported H4 \\
I <-- EC & 0.149 & 0.043 & Supported H3 \\
I <-- EA & 0.124 & 0.011 & Supported H2 \\
I <-- A & 0.077 & 0.020 & Supported H1 \\
A <-- EA & 0.150 & 0.032 & Supported H2a \\
A <-- EC & 0.263 & 0.014 & Supported H3a \\
\hline
\end{tabular}

Attitude towards the environment directly and indirectly affect the intentions through mediating role of attitude towards organic foods $\left(\beta_{2}=0.124, r=0.34\right)$. Similarly, concern for the environment directly and indirectly affect the intentions through mediating role of attitude towards organic foods $\left(\beta_{3}=0.149, \mathrm{r}=0.32\right)$.

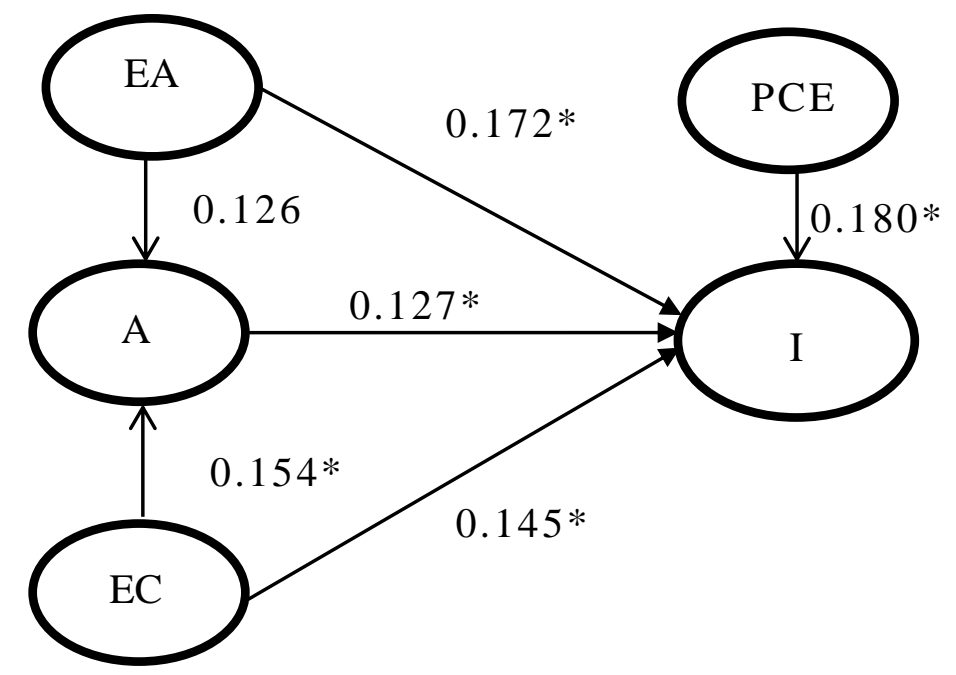

Figure 2. Structural results (standardized estimates)

Notes: * significant at $5 \%$, ** significant at $1 \%$

\section{Discussion}

Analysis of the results show that young consumers in Vietnam highly rate the aspects related to environmental such as environmental attitude, environmental concern and perceived effectiveness of environmental behaviour. Among these factors, the perceived effectiveness of environmental behaviour is the most influential to purchase intention of organic foods $\left(\beta_{\text {standardised }}=0.18\right)$. This result shows that if young consumers have belief about their actions, they can make a difference in addressing environmental issues, and the ability to perform purchase intention is higher. In other words, consumers only really intend to buy when they believe that their behavior can contribute to solve environmental problems. Conversely, if they are skeptical about the effectiveness and do not believe their actions can contribute to the environment, then their purchase intention will be declined. This result is similar to previous findings by Lee (2008), Lee (2009), 
Kim \& Choi (2005). Attitude $\left(\beta_{\text {standardised }}=\right.$ $0.172)$ and concern $\left(\beta_{\text {standardised }}=0.145\right)$ for the environment are strong influential factors to purchase intention of younger consumers. If a person with a positive attitude and concern for environment, the intention to participate in order to solve the environmental problems will be higher, such as green consumption intention. A person may be aware that green consumption behavior can contribute to their environmental improvement, but if they do not have a good attitude to the environment or do not care about the environment, the ability to perform actions will be lower. This result is consistent with the results of Lee (2008).

Attitude towards organic food positively influence to purchase intention, but it is at the lowest level compared to other factors $\left(\left(\beta_{\text {standardised }}=0.127\right)\right.$. In Vietnam organic foods are still relatively new to consumers. Therefore, the attitude and purchase intention of organic foods are rated relatively low by young consumers (average value at 3.86 and 3.56 of five-point scale). This result also implies that the increasing consumer attitude of organic foods needs to be more focused. On the one hand, attitude towards organic foods directly affects consumer intention and on the other hand it acts as a mediating role in the relationship between attitude towards the environment, concern for the environment and the purchase intention of organic foods. Therefore, the increase in the attitude and concern for the environment will result in the increase of attitude towards organic foods and the increase of purchase intention of organic foods of young consumers.

\section{Conclusions and implications}

Based on the cognitive-emotionalbehavioral framework and the theory of planned behavior of Ajzen (1991), this study examines the influence of attitude towards organic foods and environmental factors such as the attitude, concern and perceived effectiveness of environmental behaviour to young consumers' purchase intention of organic foods. The result showed that young consumers appreciate those components related to the environment such as perceived effectiveness of environmental behaviour, attitude, and concern for the environment with an average rating above 4 in the five-point Likert scale. This result indicates conformity in terms of awareness of young people with higher education levels. In particular, awareness of the effective environmental actions is the most powerful factor influencing consumers' purchase intention to organic foods, and followed by attitude towards the environment and concern for the environment.

An attitude towards organic foods was assessed at a relatively low level and the weakest influence factors to purchase intention compared to other factors by young consumers. It is easy to see that organic foods have been widely used in some developed countries, but in Vietnam, organic foods are still relatively new and not popular. Although young consumers have a high level of education, they rarely have access to organic foods. Therefore, the role of an attitude towards organic foods will become more and more important in the Vietnamese market in the future. In addition, an attitude towards organic foods plays an intermediary role in the relationship between attitude towards the environment, concern for the environment and consumers' purchase intention of organic foods. So the combination of environmental aspects in the field of organic foods is an important marketing strategy in the future.

In addition to the above results, this study has some limitations. First, this study carried out with a convenience sample in HCM City; therefore, the representative of sample might not be high. Second, the study was concentrated with young adults, as a result demographics factors haven't been evaluated. Third, this study focused on the attitude variables; hence, it might overlook some other variables in explaining consumers' purchase intention such as subjective norms, perceived behavioral control, pricing, availability. Therefore, further studies could overcome the limitations mentioned above to obtain more reliable results 


\section{References}

Ajzen, I. (1991). The theory of planned behavior. Organizational Behavior and Human Decision Processes, 50(2), $179-211$.

Ajzen, I. and Fishbein, M. (2005). The influence of attitudes on behaviour, in Albarracin, D., Johnson, B.T. and Zanna, M.P. (Eds), The Handbook of Attitudes. Mahwah, NJ: Erlbaum.

Ajzen, I., \& Fishbein, M. (1980). Understanding attitudes and predicting social behaviour. Englewood Cliffs, NJ: Prentice-Hall.

Bamberg, S. (2003). How does environmental concern influence specific environmentally related behaviors? A new answer to an old question. Journal of environmental psychology, 23(1), 21-32.

Chen, M. F. (2007). Consumer attitudes and purchase intentions in relation to organic foods in Taiwan: Moderating effects of food-related personality traits. Food Quality and Preference, 18(7), 1008-1021.

Chen, T. B., \& Chai, L. T. (2010). Attitude towards the environment and green products: Consumers' perspective. Management science and engineering, 4(2), 27-39.

Chen, Y. S. (2010). The drivers of green brand equity: green brand image, green satisfaction, and green trust. Journal of Business Ethics, 93(2), 307-319.

Dean, M., Raats, M. M., \& Shepherd, R. (2008). Moral concerns and consumer choice of fresh and processed organic Foods1. Journal of Applied Social Psychology, 38(8), 2088-2107.

Gracia, A. and de Magistris, T. (2007). Organic food product purchase behaviour: a pilot study for urban consumers in the South of Italy. Spanish Journal of Agricultural Research, 5(4), 439-51.

Kim, Y. E. O. N. S. H. I. N. (2011). Understanding green purchase: The influence of collectivism, personal values and environmental attitudes, and the moderating effect of perceived consumer effectiveness. Seoul Journal of Business, 17(1), 65-92.

Kim, Y., \& Choi, S. M. (2005). Antecedents of green purchase behavior: An examination of collectivism, environmental concern, and PCE. Advances in Consumer Research, 32, 592.

Lee K, (2009). Gender Differences in Hong Kong Adolescent Consumers' Green Purchasing Behavior. Journal of Consumer Marketing, 26(2), 87-96.

Lee, K. (2008). Opportunities for Green MarkeUng, Young Consumers. Marketing Intelligence \& Planning, 26(6), 573-586.

Saba, A., \& Messina, F. (2003). Attitudes towards organic foods and risk/benefit perception associated with pesticides. Food quality and preference, 14(8), 637-645.

Schiffman, L. G., \& Kanuk, L. L. (1987). Consumer behavior. Publisher: Prentice-hall India.

Schlegelmilch, B. B., Bohlen, G. M., \& Diamantopoulos, A. (1996). The link between green purchasing decisions and measures of environmental consciousness. European Journal of Marketing, 30(5), 35-55.

Taylor, J. R., \& Ahmed, S. A. (1974). Ecologically concerned consumers: who are they?. The Journal of Marketing, 20-24.

Taylor, S., \& Todd, P. (1995). Understanding household garbage reduction behavior: a test of an integrated model. Journal of Public Policy \& Marketing, 192-204.

Thøgersen, J. (2007). Consumer decision making with regard to organic food products, in Vaz, M.T.D.N., Vaz, P., Nijkamp, P. and Rastoin, J.L. (Eds), Traditional Food Production Facing Sustainability: A European Challenge, Ashgate, Farnham.

Vermeir, I., \& Verbeke, W. (2007). Sustainable food consumption among young adults in Belgium: Theory of planned behaviour and the role of confidence and values. Ecological Economics, 64(3), 542-553.

Yeung, S.P. (2005). Teaching approaches in geography and students' environmental attitudes. The Environmentalist, 24(1), 101-17. 